\title{
Preliminary Test on Cross Axis Type Wind Turbine
}

\author{
Endang Achdi ${ }^{1}, 3, *$, Berkah Fajar ${ }^{1}$, S. H. Winoto ${ }^{2}$, and Ibnu Lufti ${ }^{4}$ \\ ${ }^{1}$ Department of Mechanical Engineering, University of Diponegoro, Semarang, Indonesia \\ ${ }^{2}$ Faculty of Engineering, University of Diponegoro, Semarang, Indonesia \\ ${ }^{3}$ Department of Mechanical Engineering, University of Pasundan, Bandung, Indonesia \\ ${ }^{4}$ Department of Mechanical Engineering, University of 17 Agustus 1945, Cirebon, Indonesia
}

\begin{abstract}
The dependence on fossil fuel for power generation has a significant negative impact on environmental damage. To reduce the environmental damage, the use of wind energy for power generation needs to be increased and improved. A new type of wind turbine which has been reported recently is a cross axis wind turbine which can be designed for use in high-rise urban buildings where wind condition is more favorable. A model of a cross axis wind turbine which has a rotor diameter of $70 \mathrm{~cm}$ and a height of $60 \mathrm{~cm}$ has been fabricated and preliminarily tested. The wind turbine model consists of five vertical blades and two horizontal blade arrangements each having five blades. The performance test was carried out at a constant wind speed. During the test, the blade pitch angle was varied from $20^{\circ}$ to $60^{\circ}$ and wind speed was varied from $5 \mathrm{~m} / \mathrm{s}$ to $7 \mathrm{~m} / \mathrm{s}$. Analysis and evaluation results show that the output power and efficiency of the wind turbine are affected by the blade pitch angle. At wind speed of about $7 \mathrm{~m} / \mathrm{s}$, the estimated maximum power is $0.15 \mathrm{~W}$ and maximum efficiency of only $0.17 \%$ for which the pitch angle was about $60^{\circ}$ and tip speed ratio about 0.35 .
\end{abstract}

Keywords: Wind Energy, Wind Turbine, Cross Axis Wind Turbine.

\section{Delivered by Ingenta}

\section{INTRODUCTION}

Efforts to utilize wind energy for power generation are part of developing the use of renewable energy sources. One of the goals of developing renewable energy is the improvement of power generation performance derived from renewable energy. ${ }^{2}$ At the beginning of its development, this wind turbine power is used directly, such as for pumping water and pounding grains of agricultural product. While the latest development to date, the use of wind turbines is for power plant. Wind turbines for power plant can be grouped into two types that is horizontal axis wind turbines and vertical axis wind turbines. ${ }^{6}$ In general horizontal axis wind turbines are more efficient than vertical axis wind turbines. The usage of horizontal axis wind turbines requires a large and complicated support structure. While the usage of vertical axis wind turbines require an initial boost to start spinning by itself. Both horizontal axis wind turbines and vertical axis wind turbines are designed to alter the wind energy that comes horizontally. Based on many studies, the characteristics of wind in high-rise buildings in urban areas can be approximated as wind flow in the horizontal and vertical directions. $^{3}$

The new concept design of wind turbines is need to be able to extract wind energy both coming from horizontal as well as vertical direction according to the wind characteristics in high rise buildings in urban areas. The new concept of wind turbine is designed to have the blades arranged horizontally and vertically. This new concept wind turbine is called a cross axis wind turbine. ${ }^{5}$ Currently the development of cross axis wind turbines has reached the stage of developing and testing models on laboratory conditions. From the test results to this wind turbine model shows that the efficiency of this wind turbine is still low. ${ }^{3}$ Based on the low efficiency condition of the wind turbine model, the purpose of this early stage study is to get an idea of the factors that affect the efficiency improvement. These factors are obtained by preliminary test of new model of cross axis wind turbine. From the preliminary test results are expected to increase the efficiency of wind turbine type cross axis that will be done to achieve significant result.

\section{LITERATURE REVIEW}

\subsection{Wind Power}

The wind power coming into the turbine is same as its wind kinetic energy rate of the turbine and calculated by Eq. (1) below. This wind power is linier to air density $(\rho)$ and swept area $(A)$ and the wind velocity cubed $(U)$.

$$
P=\frac{1}{2} \rho A U^{3}
$$




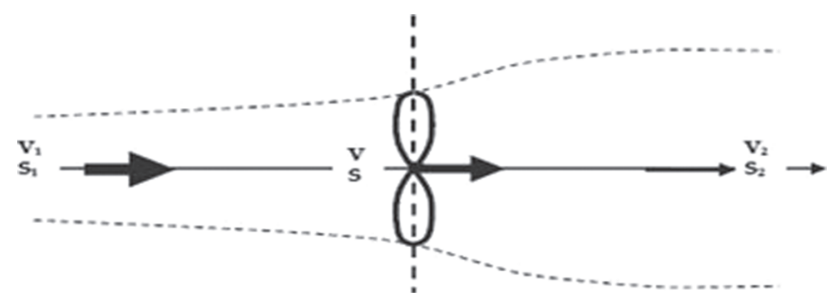

Fig. 1. Ideal wind turbine model. ${ }^{7}$

\subsection{Turbine Power}

Turbine power is wind power that extracted by turbine. This turbine power theory was introduced by a German engineer named Albert Betz as described below. ${ }^{9}$ An ideal wind turbine rotor model shown by Figure 1 above is considered the wide area of the cross section swept by the wind turbine is $S$. The area of the front side of the wind turbine is denoted by $S_{1}$ and the back side is denoted by $S_{2}$. The wind speed in the wide area of the wind turbine sweep is denoted by $V$, the front side is denoted $V_{1}$, and the rear side is denoted by $V_{2}$.

The conversion of the mechanical energy of the wind coming in by the blade rotor causes the wind kinetic energy decrease from the front side flow to the rear side. This results in a wind speed of $V_{2}<V_{1}$ or sectional area $S_{2}>S_{1}$. The air pressure at the front of the wind turbine rises and appears to drop dramatically across the turbine front side. The wind power that can be extracted by the rotor is expressed by Eq. (2) below. ${ }^{7}$

$$
P_{T}=\frac{1}{4} \rho S\left(V_{1}^{2}-V_{1}^{2}\right)\left(V_{1}+V_{2}\right)
$$

(a)

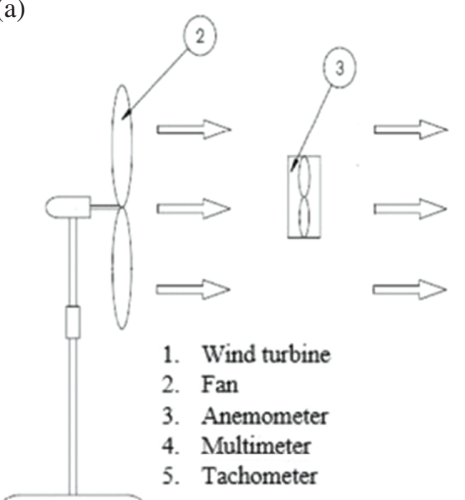

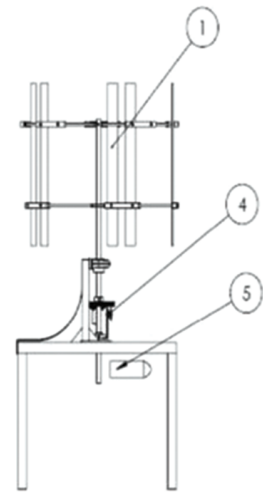

By entering the interference factor $b=V_{2} / V_{1}$ to the rotor power equation above then obtained the Eq. (3) below.

$$
P_{T}=\frac{1}{4} \rho S V_{1}^{2}\left(1-b^{2}\right)(1+b)
$$

\subsection{Power Coefficient}

The power coefficient of wind turbine is the ratio of rotor power to wind power, expressed by Eq. (4) below.

$$
C_{\mathrm{p}}=\frac{P_{T}}{P}
$$

The power coefficient can be expressed by (5) below.

$$
C_{\mathrm{p}}=\frac{1}{2}\left(1-b^{2}\right)(1+b)
$$

The maximum $C_{\mathrm{p}}$ of $59.26 \%$ obtained at $b=1 / 3$. This maximum $C_{\mathrm{p}}$ is called the Betz limit. ${ }^{8}$

\section{METHOD}

\subsection{Design of Wind Turbine}

The main stages in design of this wind turbine model are determining the number of blades, choosing the standard airfoil blade, deflector geometry, rotor dimensions, and performance calculations. These stages consider the results of existing studies with some changes. The wind turbine model design shown in Figure 2 below has 15 blades, airfoil blades using the standard NACA 0012 and NACA 4412, the shape of the curved deflector, and the size of the rotor diameter $70 \mathrm{~cm}$ and height $60 \mathrm{~cm}$.

\subsection{Test}

The equipment set-up of wind turbine preliminary test illustrated by Figure 2(a) below. The wind turbine, fan, and

(b)

\begin{tabular}{|c|c|c|c|c|c|c|c|c|c|c|c|c|c|c|c|}
\hline \multirow[b]{2}{*}{$U(\mathrm{~m} / \mathrm{s})$} & \multicolumn{5}{|c|}{ Shaft speed (rpm) } & \multicolumn{5}{|c|}{ Voltage (V) } & \multicolumn{5}{|c|}{ Current (A) } \\
\hline & $20^{\circ}$ & $30^{\circ}$ & $40^{\circ}$ & $50^{\circ}$ & $60^{\circ}$ & $20^{\circ}$ & $30^{\circ}$ & $40^{\circ}$ & $50^{\circ}$ & $60^{\circ}$ & $20^{\circ}$ & $30^{\circ}$ & $40^{\circ}$ & $50^{\circ}$ & $60^{\circ}$ \\
\hline 5,8 & 9,8 & 27,8 & 39,7 & 44,7 & 51,6 & 0 & 0,3 & 0,4 & 0,5 & 0,7 & 0,03 & 0,08 & 0.11 & 0,12 & 0,12 \\
\hline 6,6 & 14,9 & 34,3 & 46,4 & 51,3 & 60,1 & 0 & 0,4 & 0,6 & 0,7 & 0,8 & 0,04 & 0,10 & 0,12 & 0,13 & 0,14 \\
\hline 7,0 & 21,1 & 40,6 & 51,8 & 62,1 & 67,4 & 0 & 0,5 & 0,7 & 0,9 & 1,0 & 0,06 & 0,11 & 0,13 & 0,14 & 0,15 \\
\hline
\end{tabular}

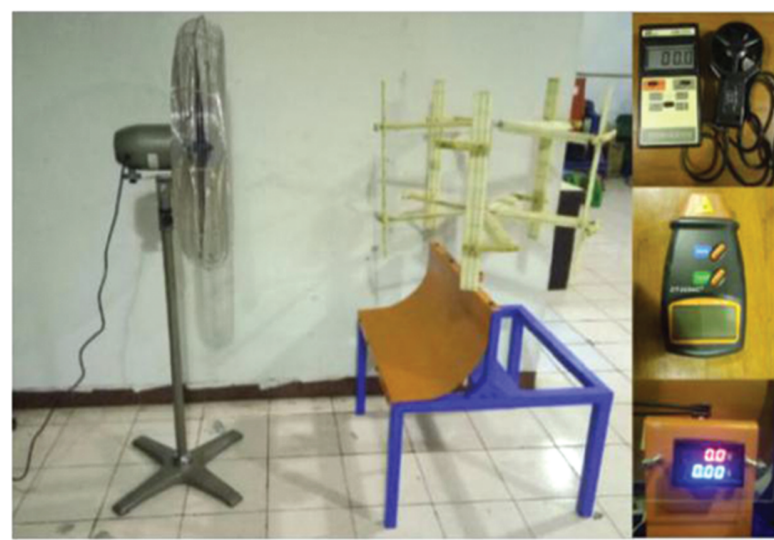

Fig. 2. (a) Test set-up and (b) wind turbine test equipment.

Table I. Test result data.

Note: $U=$ Wind velocity. 


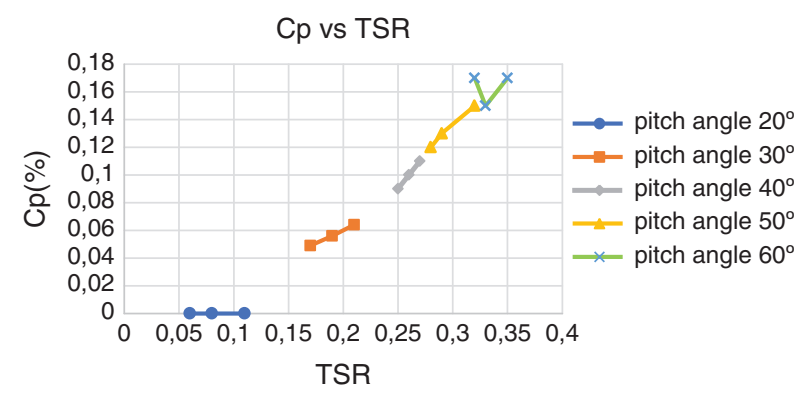

Fig. 3. Power coefficient curve to tip speed ratio.

measurement devices used in this test are shown in Figure 2(b) above.

A fan is used in this preliminary test as a wind source that is directed into the wind turbine. The wind speed of the fan can be adjusted in three positions. In the regulated wind turbine device are the five horizontal angle pitch positions. Parameters measured at each position of wind velocity and pitch angle are the rotational speed of the shaft, electric current, and the outlet voltage of the generator. All test result data can be seen in Table I above.

\section{ANALISYS AND EVALUATION}

From the test results data in Table I above can be calculated wind turbine performance parameters. These performance parameters consist of rotor angular velocity, tip tangential speed, tip speed ratio, electric power, and power coefficient. All these performance parameters are calculated for each wind speed position and blade pitch angle. The performance of the calculated wind turbine is expressed in power coefficient curve to tip speed ratio for some pitch angle in Figure 3 above.
The coefficient power of wind turbine increases by increasing of wind speed, tip speed ratio, and pitch angle of horizontal blade. From the $C_{\mathrm{p}}$ versus TSR curve above obtained a maximum $C_{\mathrm{p}}$ of about $0.17 \%$. This maximum $C_{\mathrm{p}}$ occurs at a pitch angle of about $60^{\circ}$ and a TSR of about 0.35 . The increase in wind speed and pitch angle causes the lift force on the vertical blade and the drag force on the horizontal blade increases so that the rotor power increases. The next step studies to be developed include optimization of blade arrangement, blade solidity, and pitch angle.

\section{CONCLUSION}

From the results of analysis and evaluation of this preliminary test can be concluded that the power coefficient of new model of cross axis type wind turbine influenced by tip speed ratio and angle of pitch angle. The coefficient of power increases with the increased tip speed ratio and pitch angle. Maximum power coefficient of about $0.17 \%$ is achieved at a pitch angle of about $60^{\circ}$ and a tip speed ratio of about 0.35 . This conclusion provides the basis for the next development of new model of cross axis type wind turbine to obtain higher power coefficient.

\section{References and Notes}

1. T. Burton, D. Sharpe, N. Jenkins, and E. Bossanyi, Wind Energy Handbook, John Wiley \& Sons, Ltd., Chichester, England.

2. M. Casini, Journal of Clean Energy Technologies 4 (2016).

3. W. T. Chong, M. Gwani, C. J. Tan, W. K. Muzammil, S. C. Poh, and K. H. Wong, Applied Science (2017)

4. A. T. Holomoan, Studi Kelayakan Potensi Energi Angin di Wilayah Surakarta, Program Studi Teknik Mesin, UNS Surakarta (2014).

5. B. Kekezoglu, M. Tanrioven, and A. Erduman, A New Turbine Concept: Design and Implemtation, Yeldiz Technical University, Istambul, Turkey (2015).

6. M. M. S. Magedi and A. Norzelawati, IQSR Journal Engineering 4 (2014).

7. M. Ragheb and A. M. Ragheb, Wind Turbines Theory-The Betz Limit Equation and Optimal Tip Speed Ratio, University of Illinois at Urbana, USA. 